\title{
Piccardi-Lassueur-Graham-Little syndrome associated with frontal fibrosing alopecia and lichen planus pigmentosus
}

\section{Selma El Kadiri, Hanane Baybay, Rhizlane Chaoui, Zakia Douhi, Sara Elloudi, Fatima Zahra Mernissi}

Department of Dermatology, University Hospital Hassan II, Fez, Morocco

Corresponding author: Dr. Selma El Kadiri, E-mail: elkadiri-s@hotmail.com

Sir,

A 51 -year-old postmenopausal woman presented with history of progressive hair loss over the scalp, axilla, groin and eye-brows since 3 years. Over the same period, she had noticed a darkening and mild itch on the face. However her past medical history was unremarkable.

Dermatological examination revealed a plaque of cicatricial alopecia on the scalp with a 2-cm band of recession along the frontotemporal hairline; the underlying skin was smooth and shiny (Fig. 1). Loss of eye-brows was noted (Fig. 2). Non-scarring alopecia was present over the axillar and pubic regions (Figs. 3a and 3b). Multiple follicular papules over the thighs were observed (Fig. 4). Finally gray-brown pigmented patches,non atrophic,smooth in surface with a reticular pattern located on the forehead, nose,periorbital region and cheeks were present (Fig. 5).

On dermoscopy, an exaggerated pseudoreticular pigmentary network with grey Perifollicular globules was noted for the lesion of face, while dermoscopy of the scalp showed follicular hyperkeratosis (Figs. 6a and 6b).

However nails, mucosa, palms and soles were normal.

Piccardi-Lassueur-Graham-Little syndrome associated with frontal fibrosing alopecia and lichen planus pigmentosus was diagnosed.

Blood tests including thyroid hormone profile, autoimmune tests, and viral serologies, were normal.

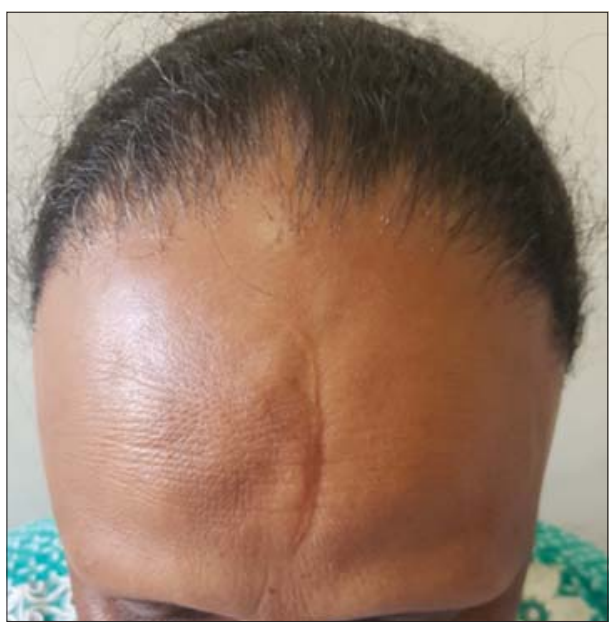

Figure 1: Plaque of cicatricial alopecia on the scalp with a recession of the frontotemporal hairline.

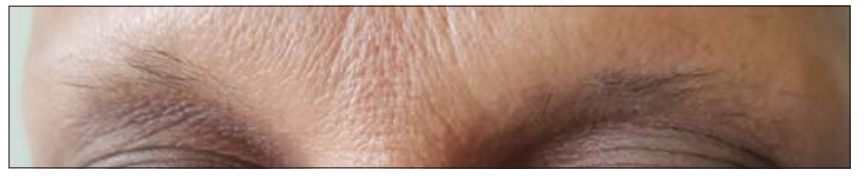

Figure 2: Loss of eye-brows

The patient was prescribed oral corticosteroid at a dose of $60 \mathrm{mg}$ once daily $(1 \mathrm{mg} / \mathrm{kg})$, and measures of sunscreen for 3 months with partial improvement.

The Piccardi-Lassueur-Graham-Little syndrome (PLGLS) first reported by Piccardi, in 1913, is a rare disorder, characterized by the triad of multifocal scarring alopecia of the scalp, keratotic follicular eruption and noncicatricial alopecia of the axilla and groin [1]. It's etiology remains unclear, but studies focusing on clinical,

\footnotetext{
How to cite this article: El Kadiri S, Baybay H, Chaoui R, Douhi Z, Elloudi S, Mernissi FZ. Piccardi-Lassueur-Graham-Little syndrome associated with frontal fibrosing alopecia and lichen planus pigmentosus. Our Dermatol Online. 2020;11(e):e64.1-e64.2.

Submission: 13.04.2020; Acceptance: 30.06.2020

DOI: 10.7241 /ourd.2020e.64
} 


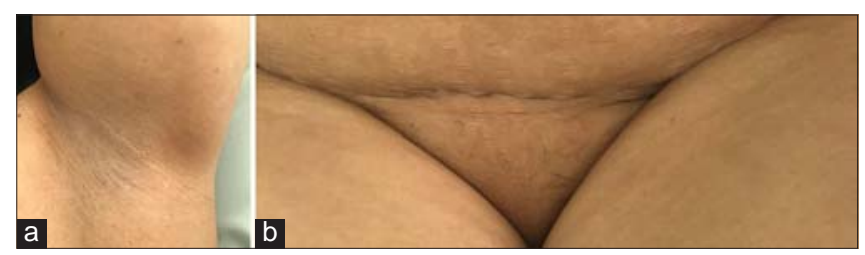

Figure 3: ( $a$ and $b)$ Non-scarring alopecia was over the axillar and pubic regions.

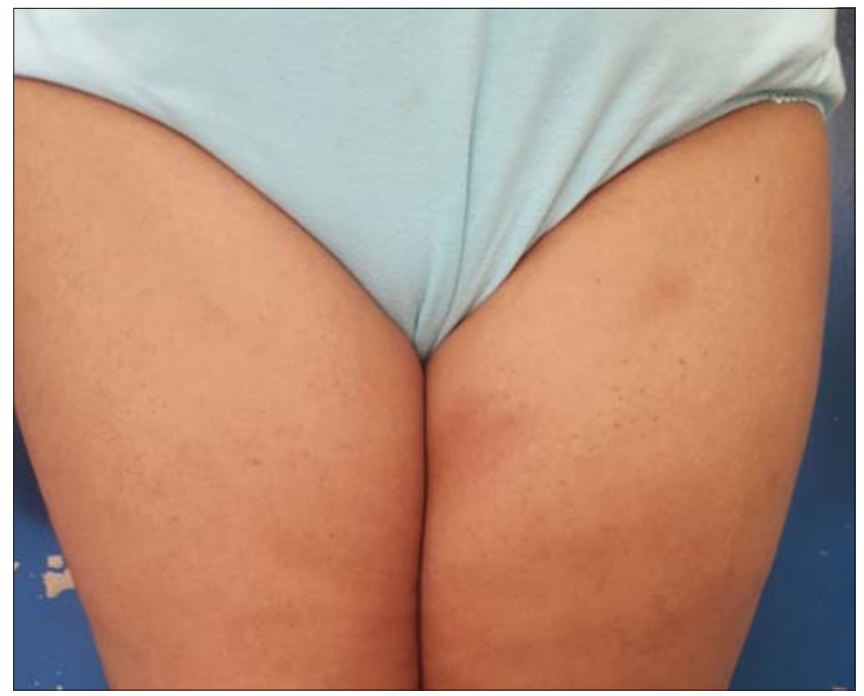

Figure 4: Multiple follicular papules over the thighs.

histological, and immunofluorescent features of PLGLS suggest that it could be a variant of lichen planopilaris [2]. Patients may present at least one episode of lichen planus or mucosa during the course of the disease [1].

Frontal fibrosing alopecia (FFA) is a primary lymphocytic scarring alopecia with a distinctive clinical pattern of progressive frontotemporal hairline recession and eyebrow loss that preferentially affects the postmenopausal women [3]. It's association with PLGLS still rarely described and uncommon.

Lichen planus pigmentosus (LPPig) is a rare variant of classic lichen planus of unclear etiology that tends to occur in middle-aged individuals with skin types III to VI [4].

To our knowledge, we report a rare association between Piccardi-Lassueur-Graham-Little syndrome, frontal fibrosing alopecia and lichen planus pigmentosus which its common pathogenic mechanism remains unclear.

\section{Consent}

The examination of the patient was conducted according to the Declaration of Helsinki principles.

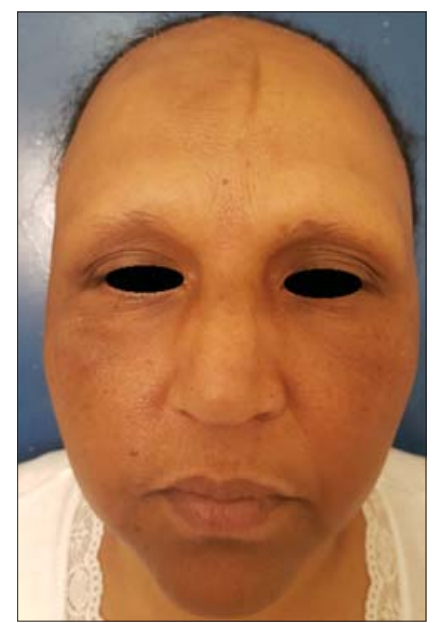

Figure 5: Confluent gray-brown pigmented patches, involving forehead, nose, periorbital region and cheeks.

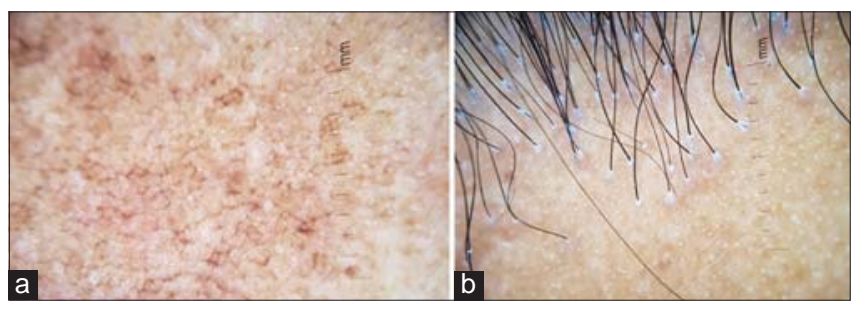

Figure 6: a) Dermoscopy of the face demonstrated an exaggerated pseudoreticular pigmentary network with gray perifollicular globules; b) Dermoscopy of the scalp with perifollicular hyperkeratosis.

The authors certify that they have obtained all appropriate patient consent forms. In the form the patient(s) has/have given his/her/ their consent for his/her/their images and other clinical information to be reported in the journal. The patients understand that their names and initials will not be published and due efforts will be made to conceal their identity, but anonymity cannot be guaranteed.

\section{REFERENCES}

1. Steglich RB, Tonoli RE, Pinto GM, Müller FM, Guarenti IM, Duvelius ES. Graham-Little Piccardi Lassueur syndrome: case report. An Bras Dermatol. 2012;87:775-7.

2. Rawat R, Mahajan VK, Chander B, Mehta KS, Chauhan PS, Gupta M. Graham Little Picardi Lassueur syndrome. Our Dermatol Online. 2016;7:114-6.

3. Piotrkowicz M, Owczarek W. Frontal fibrosing alopecia and ulerythema ophryogenes as two entites that can transist one into another. Our Dermatol Online. 2018;9:290-93.

4. Takeoka S, Tada Y, Ohnishi T, Watanabe S. Case of lichen planus pigmentosus with unique distribution. J Dermatol. 2015;42:652-4.

Copyright by Selma El Kadiri et al. This is an open access article distributed under the terms of the Creative Commons Attribution License, which permits unrestricted use, distribution, and reproduction in any medium, provided the original author and source are credited.

Source of Support: Nil, Conflict of Interest: None declared. 